\title{
A METHOD FOR THE DEMONSTRATION OF CALIBRE CHANGES IN THE BRONCHI IN NORMAL RESPIRATION
}

\author{
By PETER HEINBECKER ${ }^{1}$
}

(From the Department of Physiology, Washington University School of Medicine, St. Louis, Missouri)

(Received for publication April 25, 1927)

An investigation of the literature indicates that changes occurring in the calibre of the bronchi during the normal respiratory movements have never been demonstrated. In a review of the subject by von Skramlik (1925) it is remarked that one would anticipate a widening during inspiration, a narrowing during expiration, but that in quiet respiration these differences are obviously too small to record. In forced respiratory movements as in cough it is known (Brünings, 1912) that a narrowing in the bronchi occurs just at the instant that the vocal chords are forced apart.

\section{METHODS}

Within the past few years lipiodol has permitted the outlining of the bronchial tree in the living subject with great accuracy and detail (Forestier, 1926). It was therefore decided to investigate the possibility of using this substance to demonstrate any changes in the size of the bronchi which might occur during normal respiration.

For the observations on living subjects, one cat, two dogs, and five human subjects were employed. The animals were anesthetized with urethane and the oil administered by tracheal puncture. In man the films were taken in the course of diagnostic procedures. No anesthetic was required, the technique described by Singer (1926) being employed. After injection of the oil, $x$-ray films were taken in man during the actual process of breathing and also while holding the breath at the end of inspiration and at the end of expiration.

${ }^{1}$ Fellow in Medicine of the National Research Council. 
The respiratory movements were recorded by a pneumograph held around the chest by a tape and attached to a tambour. The moment of the time of exposure of the film was signalled on the record. To record accurately the time of exposure with reference to the particular phase of respiration it is well to have the kymographic marking key and the $\mathrm{x}$-ray circuit operated by the same switch, but it was not possible to arrange this in these experiments. All radiographs were taken at a constant distance, three feet, and the exposures made very short to avoid motion in the pictures.

\section{RESULTS}

Figure 1 shows a set of radiographs taken with man as the subject, the breath being held, at the end of full inspiration (film no. 1) and at the end of full expiration (film no. 2). Figure 2 was obtained also in man but with the chest in motion, the exposures being made at a time near the end of normal inspiration (film no. 1) and at a time near the end of normal expiration (film no. 2). Examination of figure 1 indicates at once that there is a demonstrable change in the calibre of the bronchi during full respiratory movements. The bronchi and bronchioles are largest at the end of full inspiration and smallest at the end of full expiration. Figure 2 shows slight, if any, change in the calibre of the bronchi. This is the normal finding in quiet respiratory movements except as shown in figure 3 . The latter taken also in man shows an interesting feature when examined in connection with figure 4 to indicate the time of the exposures. In some of the long bronchi, particularly in those to the lower lobe, there is an actual narrowing during inspiration (fig. 3 , no. 1) when compared with the film taken during expiration (fig. 3 , no. 2) even though the latter film is taken somewhat later in expiration than the first film is in inspiration. While these findings were puzzling at first, it was seen that they could be explained on the basis of passive changes. Our radiographs showed the bronchi, especially the larger ones to the lower lobe, lengthened considerably during inspiration. Ballon and Ballon (1927) have given an excellent description of the changes in position and length occurring in the bronchi during respiration. Passive mechanical changes in calibre must be the resultant of linear and radial traction. The linear changes would be 
PETER HEINBECKER

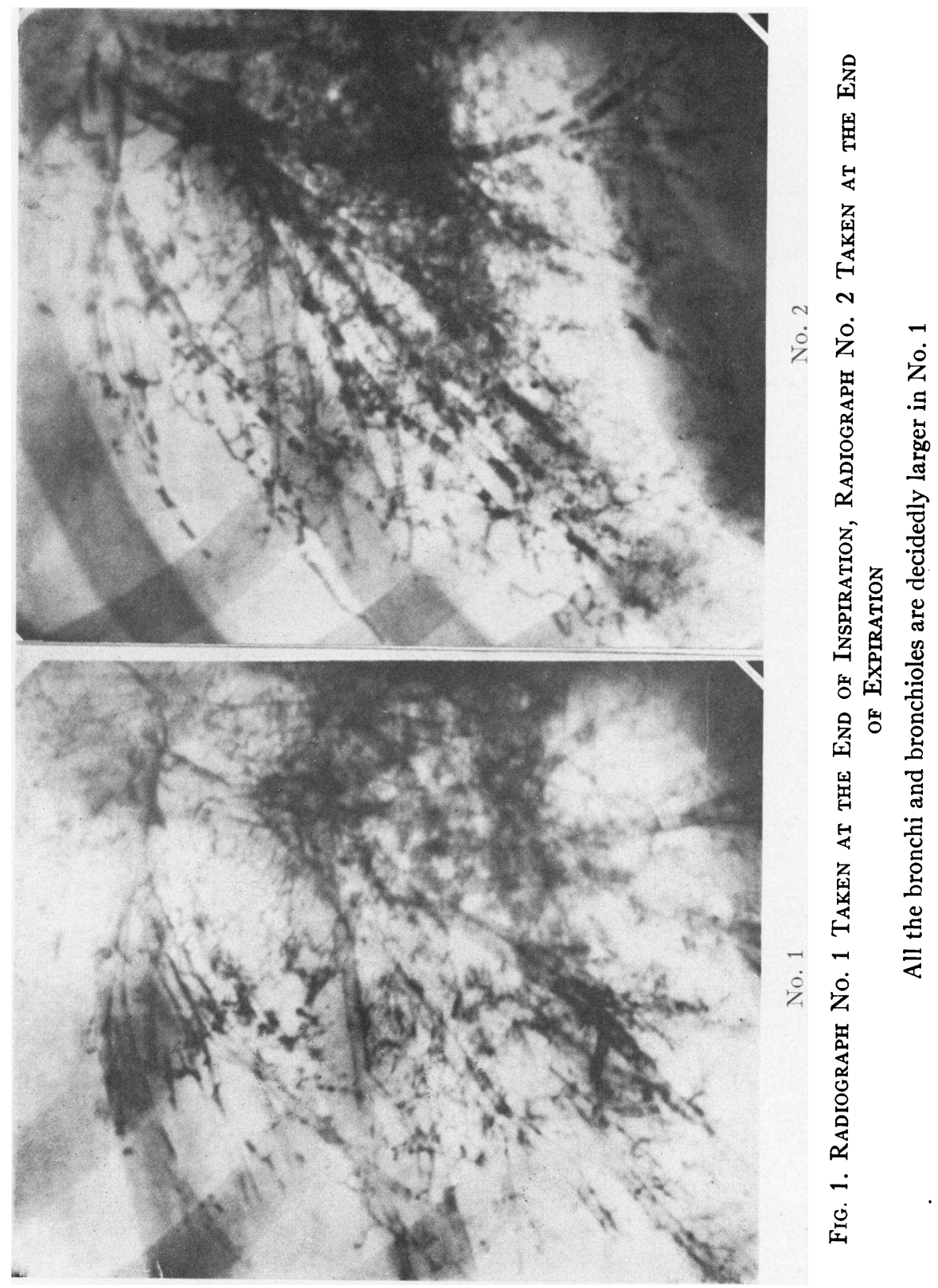




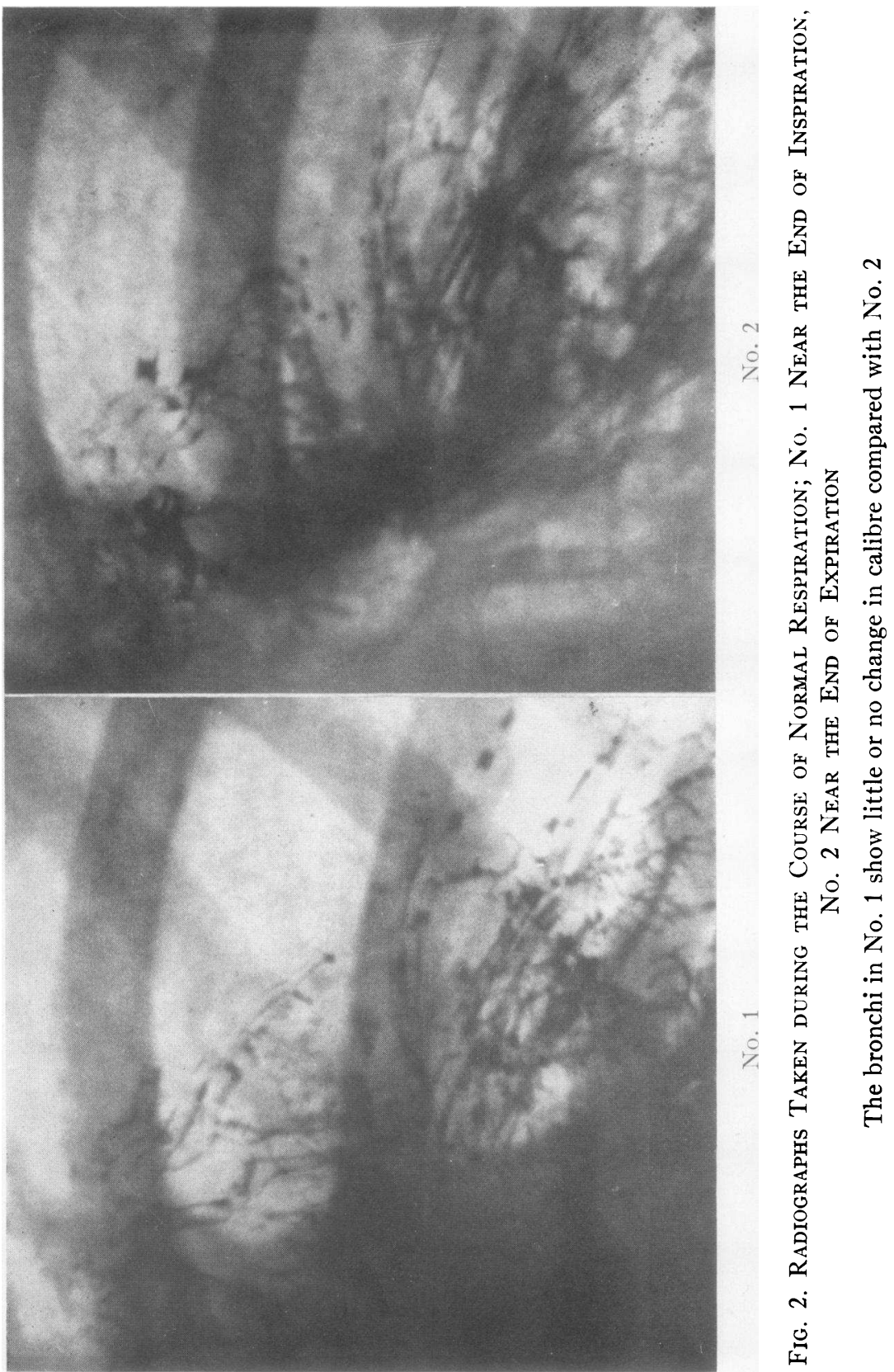




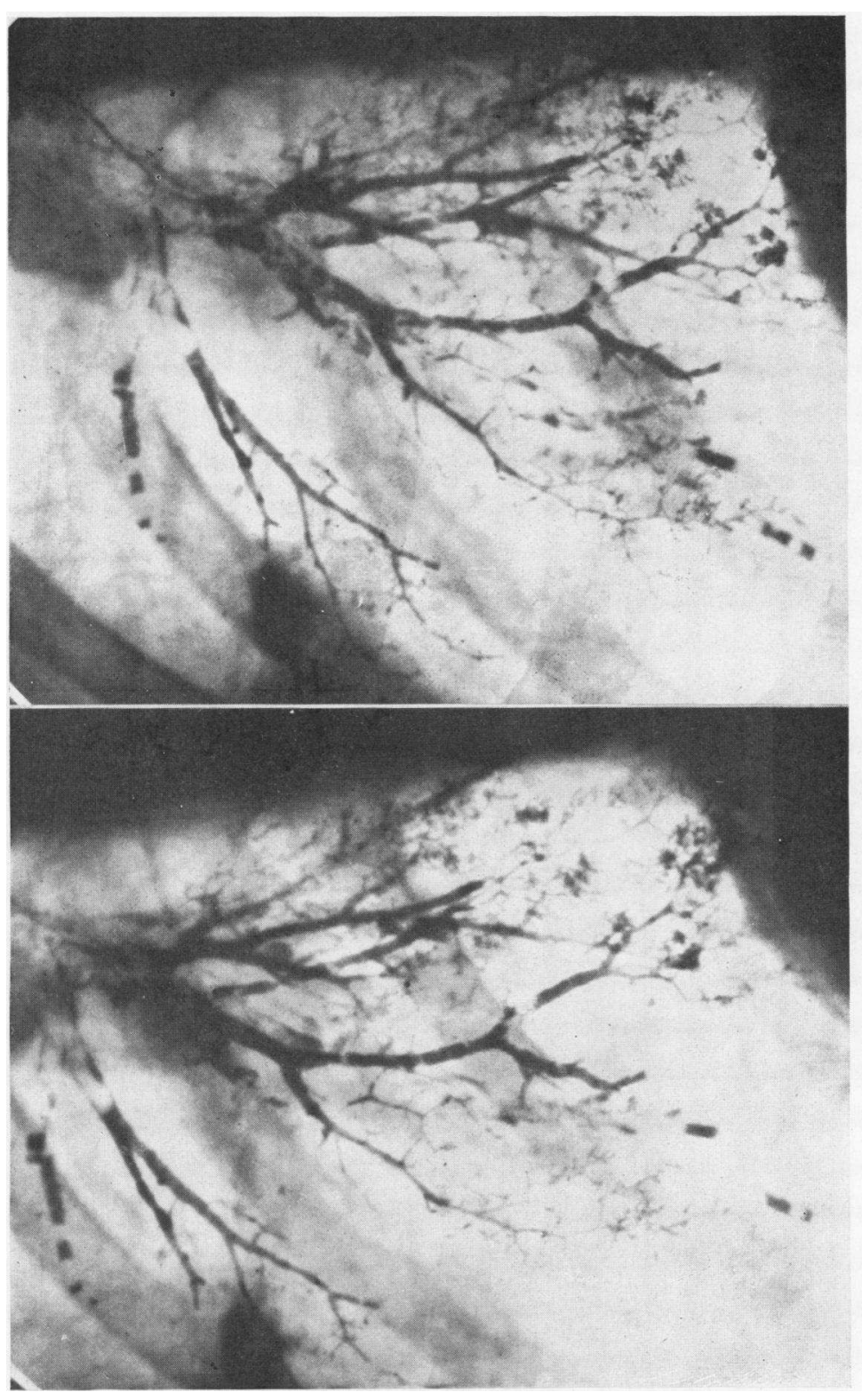

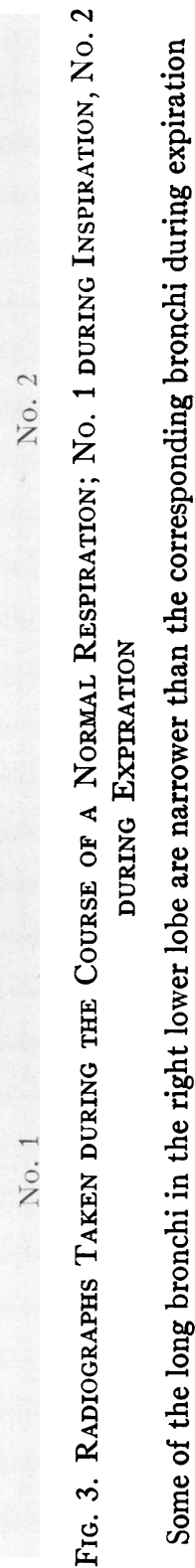


greatest at the beginning of inspiration, at the time of the descent of the diaphragm, especially with respect to the lower lobes. Radial traction would be greatest at the end of inspiration upon elevation of the ribs, when the antero-posterior and lateral diameters of the lungs are at a maximum. During quiet respiratory movements the tendency to widen during inspiration due to radial traction is prac-

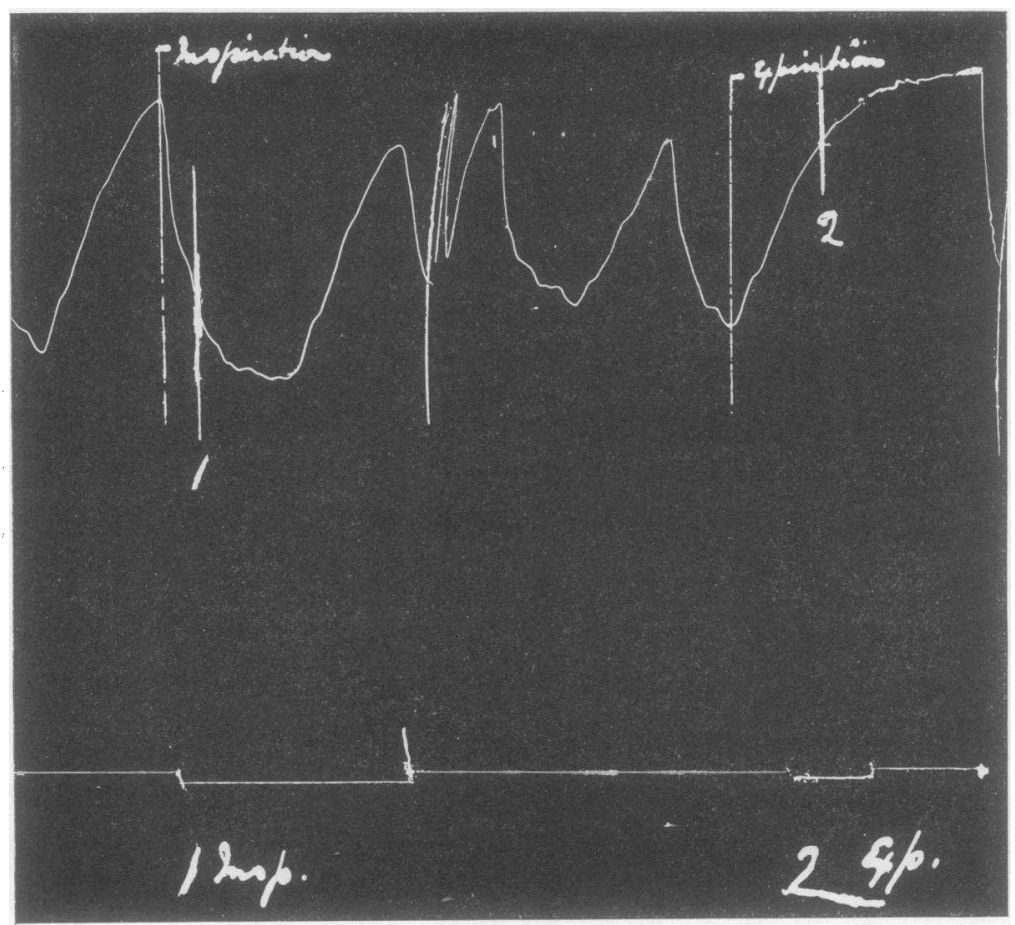

Fig. 4. Upper Tracing Indicates Respiratory Movements, Down Stroke INSPIRATION, UPSTROKE EXPIRATION

The lower line indicates the time of exposure of the x-ray films

tically equalled throughout the greater portion of the lungs by the tendency to narrow due to linear traction.

To study the passive changes which might occur in the bronchi during inflation and deflation of the lungs, experiments were performed on two cats after death. The recently killed animal was placed in a large rigid cardboard paper cylinder so fitted that exhaustion of 
PETER HEINBECKER
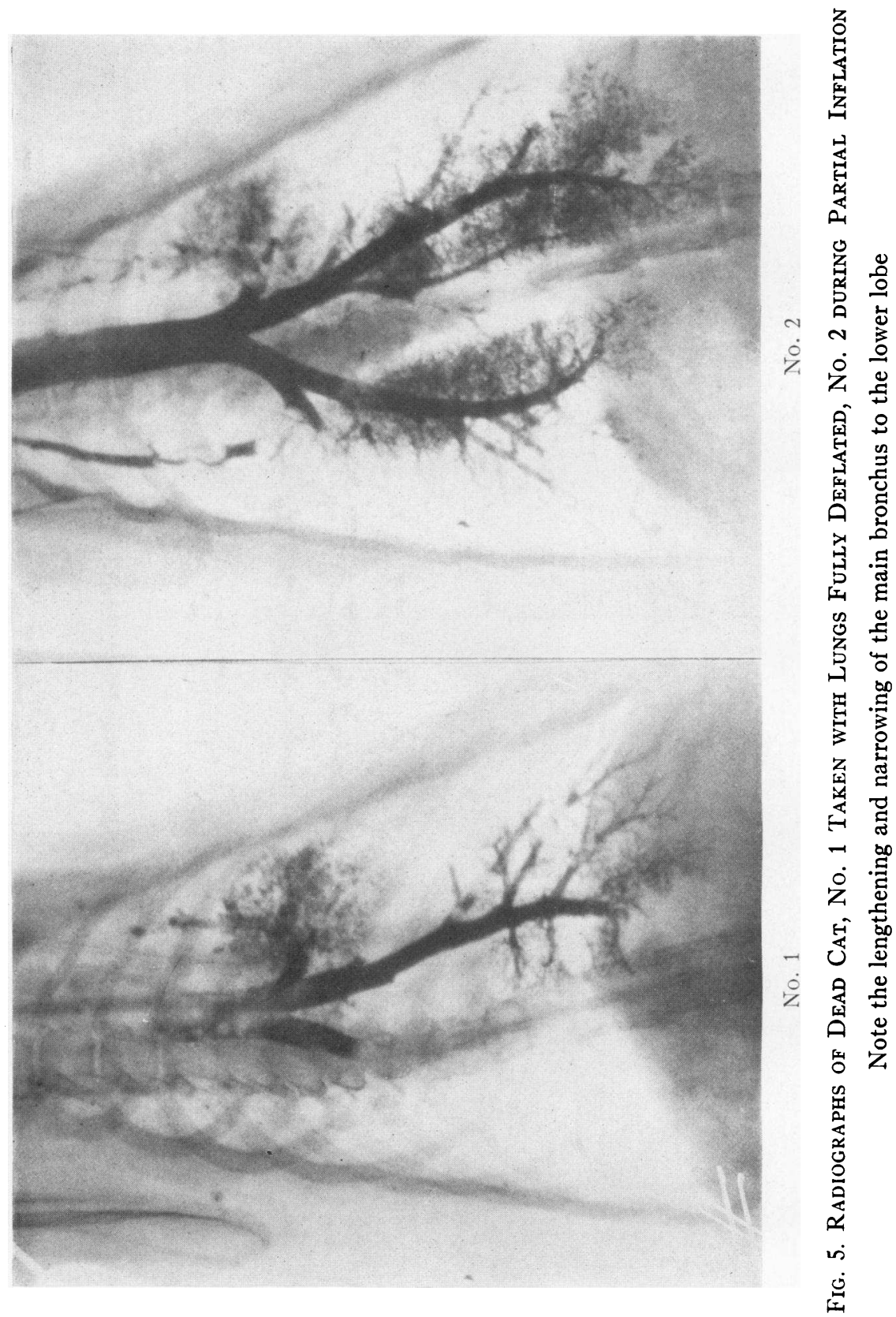

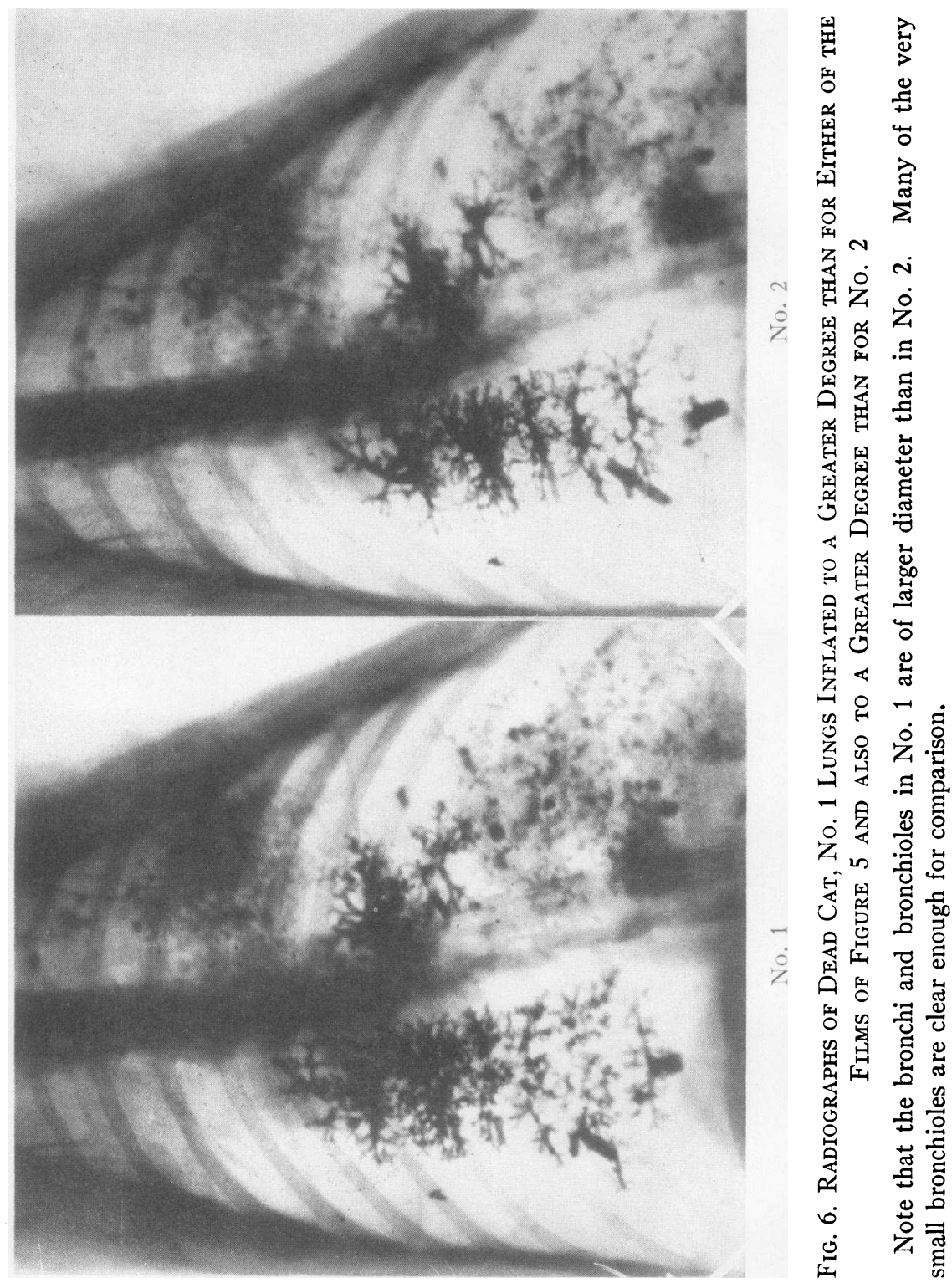
the air within the cylinder by a water suction pump was possible. A tracheal cannula, firmly tied in, opened to the atmosphere through a rubber stopper in the lid of the cylinder. Through the cannula the lipiodol was administered. Radiographs were taken with the cat's lungs inflated and deflated by negative pressure to varying degrees. A paper cylinder was used because it interfered with the passage of the $\mathrm{x}$-rays less than glass.

Figure 5 shows two films obtained in this manner. They show definitely that the elongated bronchus to the lower lobe is somewhat narrower in the inflated lung (film no. 2) than the same bronchus in the collapsed lung (film no. 1). With a greater, but not excessive degree of inflation, the bronchi are larger in the more inflated lung (film no. 1, fig. 6). The small bronchioles are well shown in these last two films and are definitely larger in the more inflated lung. One sees therefore that the longitudinal and radial changes demonstrated in the radiographs of the living lung can be paralleled in the dead lung where they are entirely passive.

The sequence of passive changes then seems to be as follows; with deflation, bronchioles shortened and narrowed (fig. 5, no. 1), with partial inflation, elongated and possibly further narrowed (fig. 5, no. 2 compared to no. 1), and with more extensive inflation, widened (fig. 6, no. 1 compared with no. 2). In the living lung any active influences would be superimposed on the changes induced by passive forces. The presence or absence of active influences in ordinary respiration can not be determined from the evidence at hand.

These changes of caliber and length are quite in keeping with anatomical considerations. Miller (1924-5) has described the course of the muscular fibers of the bronchi and shown them to circle the opening somewhat obliquely. The elastic fibers run lengthwise. The latter would then be the chief factor controlling lengthening and shortening of the bronchi, but, in addition, change of tone of the circular musculature, if it occurs, may either add to, of compensate for the passive effects due to radial traction, and may thus alter the diameters of the bronchi. If there is no active participation on the part of the bronchial musculature in ordinary respiration it would still exert its influence as an elastic structure the degree of stretching of which would vary with the degree of vagus and sympathetic tone. 
Numerous researches have shown that the calibre of the bronchi is under nervous control. Vagus stimulation causes constriction, sympathetic stimulation dilatation (Weber, 1910). L. A. Müller (1910) has demonstrated the presence of ganglion cells in the bronchial walls. With the lipiodol method we hope to investigate the question of active changes in the tone of the bronchial muscles during normal respiration and if changes occur to determine the nervous mechanism involved. There does not seem to be any reason why the method described should not also be applicable to studying changes occurring in asthma.

\section{SUMMARY}

A method is described for demonstrating changes occurring in the calibre of the bronchi during normal respiration.

The bronchi and bronchioles are widest at the end of full inspiration, narrowest at the end of full expiration. The changes are apparent chiefly at the end of the full inspiration and the beginning of the full expiration. Within the limits of quiet respiratory excursions there is practically no change in the calibre of the bronchi except during the early part of inspiration when some of the longer bronchi, particularly those to the lower lobes, are actually narrowed. Both narrowing and widening can be explained on a passive basis, as resultants of linear and radial tractions, the character and relative degree of which are determined by the manner of enlargement of the thoracic cavity during respiration. No evidence is available at present to determine the presence or absence of any active influences involving bronchial muscle tone.

The writer wishes to express to Dr. Joseph Erlanger and to Dr. George H. Bishop his appreciation for their supervision of this work.

\section{BIBLIOGRAPHY}

Ballon and Ballon, Arch. Surgery, 1927, xiv, 184. Pneumography with Iodized Oil, 40 Per Cent, by Bronchoscopic Method; Bronchial Tree, with Observations Made from 100 Injections.

Brünings, W., Die direkte Laryngoskopie, Bronchoskopie und Oesophagoskopie. Wiesbaden. Translation by W. G. Howarth, William Wood \& Co., 1912, 138. 
Forestier, J., Radiology, 1926, vi, 303. Roentgenological Exploration of Bronchial Tubes with Iodized Oil (Lipiodol).

Miller, W. S., Harvey Lectures, 1924-5, 25. Studies on the Normal and Pathological Histology of the Lung.

Müller, L. R., Deutsch. Arch. f. klin. Med., 1910, 101. Beitrage zur Anatomie, Histologie und Physiologie des Nervus vagus, zugleich ein Beitrag zur Neurologie des Herzens, der Bronchien und des Magens.

Singer, J. J., Jour. Amer. Med. Assn., 1926, lxxxvii, 1298. Simple Method of Introducing Iodized Oil into Lungs.

von Skramlik, Emil, Handbuch der normalen und pathologischen Physiologie, 1925, ii, 128. Physiologie der Luftröhre und der Bronchien.

Weber, E., Studies over det respiratorische Nerve system hos Fluesoeldyreue. Kopenhagen, 1910. Cited from L. R. Müller, "Die Lebensnerven." Zweite Auflage, 1924, 222. 